\title{
Systems, Network, and Culture
}

\author{
Dirk Baecker \\ Zeppelin University \\ Friedrichshafen, Germany \\ dirk.baecker@zeppelin-university.de \\ Presented at the International Symposium "Relational Sociology: Transatlantic \\ Impulses for the Social Sciences", Berlin, September 25-26, 2008
}

I.

Systems and network, together with rational choice, count among the most productive concepts of sociological theory in recent years. Indeed, they prove so productive that there are some who either would like to keep them apart to make sure they stay productive or to combine them to make them even more productive. As with all theoretical endeavors both ideas have something to them, as there is a mutual gain if one theory looks at the problems the other theory is addressing, but there also is a possible loss as any combination of theories may end up in a quarrel of and about notions without much regard for either social problems or empirical research. If theories tend to be products of "deep meditation" (White 2007, with respect to Luhmann's theory of social systems), it is all-important to both pursue that meditation as far as it goes and to then draw it out of its reflection and link it back to empirical research.

The interest of this paper is to keep systems theory and network theory apart for as long as their distinction in the problems they address is not fully understood, and to then only combine them if problems in social analysis appear which go beyond the problems addressed so far and merit some kind of exchange between the theories. We will try to show that phenomena of culture fit uneasily with systems theory and with network theory and may possibly be looked at within the frame of a certain reformulation of both of them we may then call a form theory.

II.

What are the problems systems theory and network theory address and how do these problems relate to the tradition of sociological theory? 
I think that it is safe to say that systems theory is contemporaneous to the advent of the computer and to its introduction to society. Both systems theory and the computer are a product of the 1940s and both share an interest in knowing and modeling devices that are able to self-organize with respect to a complex environment and an uncertain future (Wiener 1961; von Neumann 1958; von Bertalanffy 1968; Buckley 1968). Warren McCulloch was keen to name the three problems even the two mathematical geniuses of Norbert Wiener and John von Neumann were not able to solve, as there are the statistical problem of insufficient time series of data available for the understanding of social problems, the coupling of non-linear oscillators, and continuous nonlinear prediction (McCulloch 2004; cf. Baecker 2004, 2007a). Yet that does not mean that the problems already addressed by cybernetics and systems theory do not concern exactly what sociology always has been about, namely the statics and dynamics of social order in the words used by Auguste Comte (Comte 1995), or distinction in order to stabilize and indication in order to reproduce, in the words used by Niklas Luhmann to reconstruct Talcott Parsons's theory program within the terminology introduced by George Spencer-Brown (Luhmann 1980; Spencer-Brown 1994).

Network theory or at least the rising interest in it, in contrast with systems theory, seems to be contemporaneous with the appearance and introduction in the 1990s of the Internet or the World Wide Web, which is in turn supported by computers, computer grids, and computer clouds. Network theory shares with the Internet an interest in looking at and modeling both temporary and robust surprise combinations of strong ties, weak ties, and structural holes, which cut across and re-shuffle a well-defined modern order as it was once figured out by functional analysis (Granovetter 1973; Kelly 1990; Andersen 1998; Burt 1992; White 1992; Castells 1996; Fuchs 2001; Latour 2005). Most modeling problems seem to relate to blockmodels (White/Boorman/Breiger 1976; Boorman/White 1976; Wellman 1988), yet as with systems theory those problems of application do not mean that network theory as well does not concern what sociology has always been about, namely imitation and conflict in attempts to assess, maintain, and shift the identity and control of role and position, individual and discipline, style and switching (Tarde 1962, 1969; White 1992, 2008). Blockmodels attempt to capture structural equivalence of sets of ties and actors within network, such that one may understand how relations (Emirbayer 1997), among them possible relations, failed network(s), and zeroblocks prevail over personal attributes of actors.

Note that we here deliberately use the singular of network while we are using the plural of systems. Systems always come as many, as there are organic, social, mental, and artificial systems intermingling. Network seems to be only one. It means structure, and structure means expectation (Luhmann 1995a, chap. 8). Of expectations, then, there are again many, yet they 
can only be substituted by other expectations, why it is that there is only one structure. There are disciplines, domains, netdoms, and of course there are identities, ties, and relations, all, within certain limits, interchangeable, but there is only one network, I venture to say, which is the notion to describe how identities and control emerge, and how switchings are done.

It is evident that problems of difference and reproduction somehow are related to problems of identity and control, but just how they are related seems to be rather a mystery. Network theory's interest in structural equivalence, lifting, so to speak, the sociological imagination towards the self-organization of social order, certainly bears some resemblance with system theory's interest in functional equivalence, which combines shifting of problems and solutions with self-reference, and thus complexity with its reduction (Luhmann 1995a, pp. 52-8). But a search for the structural certainly leads somewhere else than a search for the functional. We do not have to believe in theory fashions, which consider both structure and function things of an essentialist and objectivist past. We know that both structure and function "allow for variation" (Fuchs 2001, p. 15 et passim). But how to combine the variables and parameters of structural equivalence with those of functional equivalence we do not know.

III.

That is why we have to start afresh. Computers and the Internet as systems and network are sure to stay with us, and we are still bound up with sociology looking at difference and reproduction, identity and control. Yet, if we look at Harrison C. White's 2008 revision of his already classical 1992 book on Identity and Control (White 2008) we may realize that there are three problems emerging, which seem and do not seem to have something in common.

There is first the problem of mathematical modeling, which White refers back to Richard Bellman's advanced engineering theory of control because here the system already consists of "nested integrations", even allowing, by distinguishing successive stages of the reproduction of the system, for some control efforts undertaken by the actors within the system (White 2008 , p. 358/9). Mathematics is an option since there is almost no better way to co-present variability within just one equation or a set of equation, and to make evident at one glance that a variable is just that, an entity with some values to it which may change according to their functional relation to some other variables. Try to do this in ordinary language, all literary subtlety notwithstanding.

There is second the problem of culture, which only recently began to be taken seriously in social studies when all kinds of "turns", the hermeneutic, the linguistic, the interpretive, the reflexive or literary, the performative, the spatial, the postcolonial, the translational, and the 
iconic turn (Bachmann-Medick 2006), were not to be overlooked anymore. Social studies are feeling uneasy with culture since they look at it as native theory of the social, even producing an awareness of distinction, contingency, and redundancy among actors, which precede and maybe go even beyond sociology's efforts (that, at least, is cultural studies' bet). Sociological systems theory only belatedly looked into culture, both into its notion within a modern society developing an interest in the comparison of historically and regionally differentiated social life-worlds (Herder) and into its function within a world society developing its own incomprehensibility (Schlegel) in order to facilitate and restrict communication across boundaries (Luhmann 1995b; Baecker 2001a, 2001b).

Culture means hegemony, but hegemony restricted to, and enacted within, interpretation and its rhetorics (White 2008, p. 374). Culture means comparison, but bound up within the limits of the discovery of the incomparable - which is the gift ethnology, the cultural observation per se, endows its objects with after having them drawn into the modern constitution of contingency. And culture means incomprehensibility, either to demand some extra effort of culture competence (among people of different language, religion, ethnicity, gender, age, wealth, or profession) to understand nevertheless or to tell one that any further effort is futile (do not underestimate the polemical subtext of cultural difference).

And there is third the problem of self-reference, somehow entangled with language, and somehow hoping for the possibility to envision grammar as an escape from paradox by giving and guaranteeing depth, that is vertical and thereby asymmetrical distinction, to context (ibid., p. $\mathrm{xx}$ and 368). Self-reference is also related to the question how to deal with observations when they are done by both the social scientist and its object (ibid., p. 337), which led the socalled postmodern movement to include at almost any prize (of readability) the narrator among the subjects s/he is writing about. I am not sure that this special problem is solved by White presenting himself rather as a playwright than as a narrator (ibid., p. 12). If the postmodern narrator has to avoid to know it better, does it help that the playwright knows about knots ( $\pi \lambda \mathrm{o} \chi \eta$, Aristotle's 1997, 1456a, term) of beginning, climax, and ending, the actors have no idea about? The problem of self-reference is at the very center of Luhmann's endeavor of a theory of social systems conceptualized as self-referential, self-organizing, and autopoietic systems, yet observers often conclude that Luhmann is more interested in staging paradox than in avoiding it. ${ }^{1}$

1 In the terminology of the confidence games analyzed by Erving Goffman, On Cooling the Mark Out: Some Aspects of Adaptation to Failure, in: Psychiatry: Journal of Interpersonal Relations 15 (1952), pp. 451-463, one may ask whether Luhmann is the first operator luring his readers into the trap of paradox or 
And if all three problems have more in common than at first leaps to the eye? What if mathematics, culture, and self-reference (both in the observer and in its subject) should rather be combined to deal with their respective problems?

White gives a stern warning to anybody approaching the realm of general systems theory in general and Spencer-Brown's calculus in particular "both of which pull one away from the main lines of science and modeling" (White 2008, p. 353), and we should take such a warning serious, since it concerns success among the academic public, yet what if there is more to be gained than to be lost? There is no need to be contrary and to enjoy sitting safely in one's more or less comfortable niche, but there is any need to work on systems, distinctions, and their form to bring them into the mainstream.

IV.

Let us start with the observer, bring then in the mathematics of self-reference, and end up with culture.

The reason to invent the observer was epistemological. The scientific discovery of complex objects like the organism, its brain, or indeed any living cell in the biology and neurophysiology of $19^{\text {th }}$ and early $20^{\text {th }}$ century was tantamount to the discovery of causality and statistics being overtaxed with dealing with these objects (Weaver 1948; Morin 1974). The concept of self-organization was introduced to picture both the way complex objects of any kind come about and the way a scientific observer has to organize, or "control", itself in order to be able to use its interaction with the subject as the literally empirical basis for any knowledge acquisition (Ashby 1958, 1981).

The observer ( $n$, i.e. neutral in English language) is the one who discovers the distinction it is drawing as the sole basis to draw any knowledge from. As that observer is a human being endowed with a brain, a consciousness, and a memory who at the same time is forced to attribute the observer capability to other complex objects as well, coming about by selforganization, be they McCulloch's pine cones, Gregory Bateson's dolphins and schizophrenics, Margaret Mead's happy sexuality among early humans or Jürgen Ruesch's nuclear families, there is soon a realization that distinctions are drawn by other observers outside the brain and the mind as well. To draw a distinction becomes a fundamental cognitive ability shared by systems in the domains of life, consciousness, and communication.

the second one cooling his readers out by telling them it all amounts to paradox anyway. Of course, some may assume Luhmann to be himself the mark deceived by the very idea of self-reference. 
And what is more, that specific human observer who is doing his and her talking and reading in the domain of language discovers as well, Karl Marx, Friedrich Nietzsche, Sigmund Freud, and Martin Heidegger did not write for nothing (Lawson 1985), that human observers, never alone ("seeking footing with each other", White 2008, p. xviii), not only draw distinctions but are drawn by distinctions as well, which they barely, and only by undertaking special reflective maneuvers which need time and cost nerves, have a chance to make accessible to themselves. That way, even the human observer is firmly embedded within cognitive domains (Gotthard Günther 1979 proposes to add "volitive" domains) that are to be conceptualized as existing outside its mind in the social, the physical, in time, and in space, inextricably entangled within themselves.

Yet, there is another warning in this field. As White warns to stay clear of general systems theory and Spencer-Brown's calculus, Heinz von Foerster, the master mind of second order cybernetics, i.e. the cybernetics of observing, and not just observed, systems, gives an equally stern warning to stay clear of complexity: if somebody is as ignorant to approach complexity, precisely defined as the overtaxing of the observer, he rightly also stays so (von Foerster 2002, p. 34, see also with respect to Luhmann ibid., p. 225/6). This is already Ashby's recommendation, when saying that with complex objects there is no need to try to "understand" them, there are only ways to "control" them - by controlling one's own distinctions in determining possible interactions with them (Ashby 1958).

We may safely obey this warning since it lets us keep the very complexity in mind we should try not to search into. And Heinz von Foerster gives us a recommendation what to search into instead, which is recursivity. The mathematics he proposes is the theory of recursive functions that became famous with chaotic, non-linear, and self-similar systems because it exhibits despite all chaos, non-linearity, and non-triviality one or more eigenvalues or even eigen-functions, which resemble a lot what we call, in ordinary life and language, an object, an idea, an institution (Von Foerster 2003; see also Kauffman 1987; Turner 1997; Abbott 2001).

If we now, having learned about the observer, its cognitive abilities, and a way to picture form within chaos, look around for a possible concept to conceive of culture without at once foregoing all epistemological subtlety gained before, we may, as I did long after I wrote most of my papers on culture (Baecker 2001), come across Bronislaw Malinowski's courageous and at once forgotten attempt to present us with a "scientific theory of culture", published at the height of the second World War, which does exactly what we would like it to do (Malinowski 1944). Its ambition only met afterwards by Talcott Parsons's theoretically much more sophisticated attempt to model the "human condition" with respect to its physical, 
biological, personal, and social embeddings (Parsons 1978), Malinowski's concept of culture addresses nothing less but the fact that the social organization of human life, action, and communication exhibits a wealth of variables, all of whose values have to be determined this or that way, such that a mechanism is needed, which guarantees the switching, shifting, and fixing that gives all variables a new value as soon as one of them due to environmental change or internal events should change. Culture is the name Malinowski gives to this mechanism, which, accordingly, is at least a third-order mechanism, since there are activities first, then their organization according to needs, constraints, and possibilities, and only then the mutual adaptation among the values the variables get by being organized.

Culture, with its near monopoly on the getting of action based on interpretation, 2 is the mechanism cognitive sciences should look for if they were eager to not just account for the one system reference of the brain, but for other systems references like the mental (distinct from the brain), the organic, and the social as well. To be engaged with culture means to reach across neatly separated system references without denying their existence. That is why cultural critique from Jean-Jacques Rousseau to Matthew Arnold and Theodor W. Adorno was able to ask the question of human happiness and unhappiness, which also combines mental, body, and social references and was accordingly frowned upon by the orderly physician, psychologist, and sociologist.

And this is our idea. Why don't we quite simply start with a first form picturing any social organization, which is (a) a distinction, (b) our, the observer's, distinction, (c) an eigen-form reproduced by an otherwise chaotic, non-linear, and non-trivial, or stochastic system of communication and action, and thus (d) a self-similar structure helpful in guiding actors engaged with social action? Why don't we ask of this first form that it may combine symmetry of exchange between the variables it entails with asymmetry of order giving it depth with respect to a distinction of context? And why don't we even ask of this first form that it may show involution, differentiation, and dependency, that is style, institution, and control (White 2008, p. 355), in a first rather elementary way?

Look at this Spencer-Brown expression. It tells you how two variables, $x$ and $y$, out of a set of possible further variables are to be distinguished and contextualized within a space defined by constraints defined within the frames of life, consciousness, and communication. Those frames in turn are not the biological, psychological, and sociological facts, if there were such

2 Artists, entrepreneurs, politicians, and more of the heroes of the chapter 7 of White 2008 indeed are no exception from the rule but cultivators of their own as soon as the get fresh action via a recombination of the ways accepted until now. Anything else is stochastic, which does not mean it should be taken for nothing, since it may well fuel evolution, that is selection and retention by further interpretive action. 
things, able to tell which values the variables $x$ and $y$ should assume, but are contexts, or boundary conditions set, explored, and exploited by $x$ and $y$. To be sure, there is nothing arbitrary involved, yet neither is there any predetermined determination. That is why philosophical anthropology came up with its talk of the plasticity of human life (Gehlen 1988). There is an interdependence of variables, which Malinowski called a "function" in the exact mathematical sense that all variables should be looked up to determine just one of them:

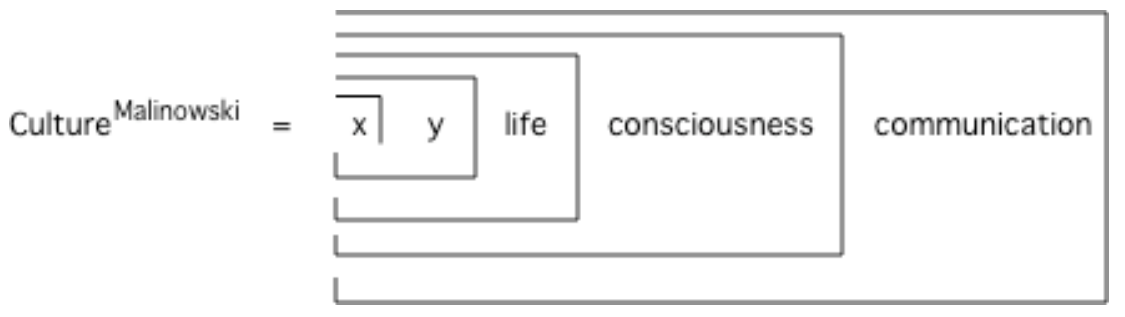

The equation tells us that (at least) two variables, $x$ and $y$, are contextualized one, $x$, by the other, $y$, and both again, i.e. their interdependence, by an interplay of the three variables of life, consciousness, and communication, or of the organic, the mental, and the social. All the variables, beginning with the two first variables, $x$ and $y$, say a funeral ritual and a government intervention forbidding Muslim clerks to help bury non-Muslim corpses (Geertz 1973), are distinguished in depth of space, such that the values of $x$ and $y$ are horizontally interdependent within one and the same social practice, while all the same the value of $x$, here standing in space $s_{5}$, is vertically controlled by the value of $y$, standing in space $s_{4}$.

The two variables of $x$ and $y$ are contextualized by three other variable standing in the spaces, $s_{3}$, life, $s_{2}$, consciousness, and $s_{1}$, communication. The deeper the space the more determinations the respective variable has to account with. One may count the number of determinations by counting the number of crosses the variable is placed under.

Note, however, that this is only one possible way to picture the interplay. There may be other perspectives on which variable is standing in which space; there may also be perspectives that omit some variable, e.g. consciousness, as William James (1922) would have it (though he would not deny it a function), ${ }^{3}$ or omit both life and consciousness, as most of sociology would rather prefer (indeed then talking of action rather than of communication). Biologists, and neuroscientists among them, may give life (short, in this case, for the neurophysiology of the brain) the shallowest space, relegating consciousness and communication to finding out what life expects from them, all the while nevertheless giving 
life a style that depends on how consciousness and communication think and talk about it (e.g., giving it biological preeminence with respect to consciousness and communication). Psychologist and, most notably, philosophers may instead opt for consciousness, sociologists for communication (or, indeed, action) as resident of the shallowest space exhibiting the least degrees of freedom.

One may also avoid such difficult choices and opt without further ado for "mind" as a catchall phrase for the life of conscious communication, as Dilthey's hermeneutics or Bateson's epistemology would have had it (Dilthey 1988; Bateson 2000). Dilthey's notion of mind gave an almost materialistic, at least a historical reading of Hegel's philosophy of mind, the dialectics of which, in their turn, went a long way to help Kant's philosophy of pure reason out of their deadlock in the self-reference of transcendental categories. Bateson's notion thinks about mind as being the domain (or medium?) of a possible differentiation within information, learning, and evolution. Yet, if there is a point to general cognitive sciences beyond the fundamentalism given to them by neuroscientists, it resides in distinguishing the mind with respect to empirical systems such as the organic, the brain, the consciousness, and the social that are subject to possible observation.

Note that there is a space $s_{0}$, which is unmarked as the outside of the form and which may well invite observers to mark it by putting in there an intelligent design, evolution, or some entity like Gaia. That is up to the observer who is thereby revealing both itself and its preferences and of course producing a new unmarked state just at the outside of the form the observer is calling forth. Our form as well is an equation indicating and distinguishing, while venturing a hypothesis about culture, an observer who is observing this way. There is no need to avoid the self-implication of the observer into the form it is advancing, since this is anyway the only way to deal with, i.e. to control, a complex object such as culture. Yet, there is every need to be explicit about your choices. Since we are dealing with systems references being abstractions within network synthesis we may well check for the scope of these abstractions in order to be able to choose sanity along with it (Korzybski 1994).

To get back to White's short list of "embeddings within three dimensions" (White 2008, p. $354 / 5$ ) we get involution by $x$ being contextualized by, and being re-entered into its space together with, $y$, which at the same time defines the style of $x$ as being determined by its neighborhood with $y$. Differentiation at once is evident by looking at the expression, institution coming from the re-entered distinction being self-similarly reproduced as the eigen-value of a recursive function embedded within the autopoiesis of society. And dependency is evident as well, since there is no $x$ without a $y$, and vice versa, such that the identities of $x$ and $y$ are mutually controlled by each other. 
Note that our Spencer-Brown expression for a Malinowski culture attempts to solve old riddles about the distinction between culture and society, or between culture and social system. We reject the truce between Harvard anthropology and Harvard sociology trying to tell culture and society apart by saying that the latter refers to all "relational" aspects of interaction among individuals and groups, and the former to "symbols", which somehow creatively generate meaning, which then is transmitted from generation to generation (Parsons/Kroeber 1958). The cultural turns quoted above, most notably its performative and interpretive versions, did put an end to distinctions like the one between symbol and relation, since symbols relate, and relations symbolize. We propose instead to stick with the notion that culture indeed specifies distinct relations within society (Parsons 1973; Rehberg 1986), and that its distinction indeed stems from its references to life and consciousness, or to the body and the mental (Kroeber 1952). With respect to these references dealt with in a way such that the social, the mental, and the organic become once again facts of co-evolution, not only binary, but ternary and quaternary oppositions constituting patterns of culture that combine depths of different levels get into the focus of social research (Kroeber/Kluckhohn 1963, p. 325-334).

White's and Frédéric C. Godart's remark that perceptions are generated from the process of switching from netdom to netdom, which they put forward as their introduction to a discussion of the concept of culture, then becomes all the more revealing (White/Godart 2007 , p. 3). Those netdoms are in no way restricted to purely social ones. Netdoms, like Wittgenstein's "life forms" perhaps (Cavell 1989), encompass control efforts embedded within interactions among several domains. If "cats" are social ones (White 2008b), "nets" certainly exist among all kinds of domains able to self-organize. That of course brings us back full circle to the question why we are so interested in network theory in the first place. If indeed "netdom", just like Luhmann's "communication", "presupposes the mixture of relation and topic, plus understanding" (White 2008a, p. 7), ${ }^{4}$ we may end up with more complex units than just humans participating within both relations and understanding (Latour 1993), such that maybe only the topics are truly ours.

Culture, then, becomes a notion, which describes the human involvement and engagement with the boundaries of society. Those boundaries mean network, if we follow Athanasios Karafillidis' proposition about networks not having but being boundaries (Karafillidis, this symposium), while the notion of systems refers to recursive operations of self-organization

4 Maren Lehmann made me aware once more of White's equation of netdom with communication proposed. 
restricted within boundaries to certain domains, the living, the mental, the social, and the artificial among them. The notion of society describes features of self-organization discovered within the domain of the social, yet there may indeed be no need to then restrict the discoveries to exactly that domain (Baecker 2007b).

V.

Let me add in concluding that this very first and simple Spencer-Brown expression for a Malinowski culture already goes a long way in picturing classical sociology's main problems, as there are the problem of difference within reproduction, and the problem of identity within control. That is why form theory, if we give it that name, and if we understand by form a selfreferential eigen-value of a recursive function embedded within an otherwise complex, i.e. stochastic, non-linear, and non-trivial, autopoiesis of society, may go some way to capture the imagination and conceptual apparatus of both systems theory and network theory. The eigenvalue is only to be produced and reproduced by a system. And the shifting, evasive, subversive, and indeed unavoidable interdependence of the values of the variables is only to be guaranteed by a network, which produces its own synthesis, relying on structural and functional equivalences and demanding, as it were, the occasional observer firmly prejudiced in its choices and bringing its determination to that otherwise free floating form (Kauffman 1978, p. 182).

Yet, a form theory of this kind may bring sociology within the realms of both cognitive studies and cultural studies in that we again begin to deal with values we somehow had learned to avoid by looking at structure instead. Values, and culture with them (Luhmann 1997, pp. 340-4, and 408-11), may well turn out to be a subject of social science studies that combine empirical concreteness with theoretical clout. We may deal with values that are determined both by the essential variables of systems reproduction W. Ross Ahby spoke about in pointing to their distribution across organism and environment (Ashby 1960) and by the parameters singled out by network theory to be able to look at functions combining identities within their domain of control (White 2000). Yet, for this we have to look at systems, network, and culture. The "topics" White is interested in, may turn out to be not just "catnets", but indeed "catjects" (Baecker 2007/8), if the latter act recursively like tradition's cherished subjects and objects, yet "with impact so awesome that participants cannot bring it into focus" (White 2008a, p. 7) constitute the eigen-forms we may then try to bring into sociological and cultural theory's focus. 
Note, in concluding, that the Malinowski formula of culture being a function interlinking and indeed knotting into each other social objects of any kind, on one hand, with the dynamics of life, consciousness, and communication, on the other, may go a long way towards an understanding of the problems of interpretation and valuation so puzzling for a sociology of culture. Value in its singular form may eventually come to be seen as determined by the interplay of communication, consciousness, and life, values in their necessary plurality being the outcome and basis for an exploration and exploitation of that interplay (see also Luhmann 1997a, pp. 408/9), and interpretation being our way to both fix and untangle the stories, disciplines, styles, and regimes of that interplay. As Harrison C. White suggests in his concluding remarks to this symposium, stories, disciplines, styles, and regimes may be distinguished by closures added as we move from loosely told and loosely coupled stories to disciplines adopting valuation for purposes of framing quality, purity, and prestige (White 1992, pp. 16/7), to styles syncopating complexity into identity (White 2008, chap. 4), and eventually to regimes and even hegemony combining styles around institutions (White 1992, p. 226).

Structural sociology would eventually merge with cultural sociology, as suggested also by Stephan Fuchs (2001), because there is no structure, which does not emerge out of, and insists on, certain valuations to be reproduced both within and outside their frame of interpretation. As soon as one is able to watch quality as an eigen-value non-linearly produced and reproduced within a recursive function, which captures the stochastic nature of social process, Nadel's paradox (DiMaggio 1992) is dissolved into a distinction of the memory of the social, on one hand, from its oscillation, on the other (for "memory" and "oscillation", see Luhmann 1997b). This would bring us one step further towards both systems and network theory's attempts to understand a calculus in trade-offs in uncertainty distinguishing between ambage and ambiguity (White 1992, p. 17-19).

Friedrich Nietzsche urged us to keep clear of causality and to adopt aesthetic terms to account for the differentiation of the organic, the mental, and the social just to understand the dance each one sphere is staging and all of them are staging together (Nietzsche 2006). As systems enact closure to oscillate and memorize, and as the network synthesizes by drawing on both ambage and ambiguity, culture is the way to invest the ensuing dances with identities, which last as long as they succeed in control among each other. 


\section{Bibliography:}

Abbott, Andrew (2001): Chaos of Disciplines, Chicago: Chicago UP.

Andersen, Peter Bøgh (1998): WWW as Self-Organizing System, in: Cybernetics and Human Knowing 5, no. 2 , pp. 5-41.

Aristotle (1997): Poetics, transl. Malcolm Heath, London: Penguin Classics.

Ashby, W. Ross (1958): Requisite Variety and Its Implications for the Control of Complex Systems, in: Cybernetica 1, pp. 83-99.

Ashby, W. Ross (1960): Design for a Brain: The Origin of Adaptive Behavior, $2^{\text {nd }}$ rev. ed., New York: Wiley.

Ashby, W. Ross (1981): Principles of Self-Organization, in: idem, Mechanisms of Intelligence: W. Ross Ashby's Writings on Cybernetics, ed. Roger Conant, pp. 51-74.

Bachmann-Medick, Doris (2006): Cultural Turns: Neuorientierungen in den Kulturwissenschaften, Reinbek b. Hamburg: Rowohlt.

Baecker, Dirk (2001a): Wozu Kultur? 2 ${ }^{\text {nd }}$, enl. ed., Berlin: Kulturverlag Kadmos.

Baecker, Dirk (2001b): Kultur, in: Karlheinz Barck et al. (eds.): Ästhetische Grundbegriffe: Historisches Wörterbuch in sieben Bänden, Stuttgart: Metzler, pp. 510-556.

Baecker, Dirk (2004): Rechnen lernen: Soziologie und Kybernetik, in: Claus Pias (ed.), Cybernetics: The Macy Conferences 1946-1953, vol. 2: Essays and Documents, Zürich: diaphanes, pp. 277-298.

Baecker, Dirk (2007a): Knowledge and Ignorance: The Heinz von Foerster Lecture 2003, in: Albert Müller and Karl H. Müller (eds.), An Unfinished Revolution? Heinz von Foerster and the Biological Computer Laboratory I BCL 1958-1976, Wien: edition echoraum, pp. 337-350.

Baecker, Dirk (2007b): Die Natur der Gesellschaft, in: idem, Wozu Gesellschaft? Berlin: Kulturverlag Kadmos, pp. 10-28.

Baecker, Dirk (2007/8): The Network Synthesis of Social Action, Part I: Towards a Sociological Theory of Next Society, and Part II: Understanding Catjects, in: Cybernetics and Human Knowing 14, no. 4, pp. 9-42, and 15 , no. 1 , pp. 45-65.

Bateson, Gregory (2000): Steps to an Ecology of Mind, Reprint Chicago: Chicago UP.

Boorman, Scott A., and Harrison C. White (1976): Social Structure from Multiple Networks, Part II: Role Interlock, in: American Journal of Sociology 81, pp. 1384-1446.

Buckley, Walter (ed.) (1968): Modern Systems Research for the Behavioral Scientist, Chicago: Aldine.

Burt, Ronald S. (1992): Structural Holes: The Social Structure of Competition, Cambridge, Mass.: Harvard UP.

Castells, Manuel (1996): The Rise of the Network Society, Oxford: Blackwell.

Cavell, Stanley (1989): Declining Decline: Wittgenstein as a Philosopher of Culture, in: idem, This New Yet Unapproachable America: Lectures after Emerson after Wittgenstein, Albuquerque, NM: Living Batch, pp. 29-75.

Comte, Auguste (1995): Leçons sur la sociologie: Cours de philosophie positive, Leçons 47 à 51, ed. Juliette Grange, Paris: Flammarion.

Dilthey, Wilhelm (1988): Introductio to the Human Sciences: An Attempt to Lay a Foundation for the Study of Society and History, transl. Ramon J. Betanzos, Detroit: Wayne State UP.

DiMaggio, Paul (1992): Nadel's Paradox Revisited: Relational and Cultural Aspects of Organizational Structure, in: Nitin Nohria and Robert G. Eccles (eds.), Networks and Organizations: Structure, Form, and Action, Boston, Mass.: Harvard Business School Pr., pp. 118-142.

Emirbayer, Mustafa (1997): Manifesto for a Relational Sociology, in: American Journal of Sociology 103, pp. 281-317.

Fuchs, Stephan (2001): Against Essentialism: A Theory of Culture and Society, Cambridge, Mass.: Harvard UP.

Geertz, Clifford (1973): Ritual and Social Change: A Javanese Example, in: idem, The Interpretation of Cultures: Selected Essays, New York: Basic Books, pp. 142-169.

Gehlen, Arnold (1988): Man, his Nature and Place in the World, transl. Clare McMillan and Karl Pillemer, introd. Karl-Siegbert Rehberg, New York: Columbia UP.

Granovetter, Marc (1973): The Strength of Weak Ties, in: American Journal of Sociology 78, pp. 1360-1380.

Günther, Gotthard (1979): Cognition and Volition: A Contribution to a Scientific Theory of Subjectivity, in: idem, Beiträge zur Grundlegung einer operationsfähigen Dialektik, vol. 2, Hamburg: Meiner, pp. 203240.

James, William (1922): Does "Consciousness" Exist? In: idem, Essays in Radical Empiricism, $2^{\text {nd }}$ ed., New York: Langman, Green \& Co., pp. 1-38. 
Karafillidis, Athanasios (this symposium): Networks and Boundaries.

Kauffman, Louis H. (1978): Network Synthesis and Varela's Calculus, in: International Journal of General Systems 4, pp. 179-187.

Kauffman, Louis H. (1987): Self-Reference and Recursive Forms, in: Journal of Social and Biological Structures: Studies in Human Sociobiology 10, pp. 53-72.

Kelly, Kevin (1990): Out of Control: The New Biology of Machines, Social Systems, and the Economic World, Redwood City, CA: Addison-Wesley.

Korzybski, Afred (1994): Science and Sanity: An Introduction to Non-Aristotelian Systems and General Semantics, fifth ed., Lakeville, Conn.: Institute of General Semantics.

Kroeber, Alfred L. (1952): The Nature of Culture, Chicago: Chicago UP.

Kroeber, A. L., and Clyde Kluckhohn (1963): Culture: A Critical Review of Concepts and Definitions, Reprint New York: Vintage Books.

Latour, Bruno (1993): We Have Never Been Modern, transl. Catherine Porter, Cambridge, Mass.: Harvard UP.

Latour, Bruno (2005): Reassembling the Social: An Introduction to Actor-Network Theory, Oxford: Oxford UP.

Lawson, Hilary (1985): Reflexivity: The Post-Modern Predicament, London: Hutchinson.

Luhmann, Niklas (1980): Talcott Parsons - Zur Zukunft eines Theorieprogramms, in: Zeitschrift für Soziologie 9, pp. 5-17.

Luhmann, Niklas (1995a): Social Systems, transl. John Bednarz with Dirk Baecker, Stanford, CA: Stanford UP.

Luhmann, Niklas (1995b): Kultur als historischer Begriff, in: idem, Gesellschaftsstruktur und Semantik: Studien zur Wissenssoziologie der modernen Gesellschaft, vol. 4, Frankfurt am Main: Suhrkamp, pp. 31-54.

Luhmann, Niklas (1997a): Die Gesellschaft der Gesellschaft, Frankfurt am Main: Suhrkamp.

Luhmann, Niklas (1997b): The Control of Intransparency, in: System Research and Behavioral Science 14, pp. 359-371.

Malinowski, Bronislaw (1944): A Scientific Theory of Culture and Other Essays, with a Preface by Huntington Cairns, Chapel Hill, NC: North Caroline UP.

McCulloch, Warren S. (2004): The Beginning of Cybernetics, in: Claus Pias (ed.), Cybernetics: The Macy Conferences 1946-1953, vol. 2: Essays and Documents, Zürich: diaphanes, pp. 345-360.

Morin, Edgar (1974): Complexity, in: International Social Science Journal 26, pp. 555-582.

Nietzsche, Friedrich (2006): On Truth and Lies in a Nonmoral Sense, in: Keith Ansell-Pearson and Duncan Large (eds.), The Nietzsche Reader, Malden, Mass.: Blackwell, pp. 114-123.

Parsons, Talcott (1973): Culture and Social System Revisited, in: Louis Schneider and Charles M. Bonjean (eds.), The Idea of Culture in the Social Sciences, Cambridge: Cambridge UP, p. 33-46.

Parsons, Talcott (1978): A Paradigm of the Human Condition, in: idem, Action Theory and the Human Condition, New York: Free Pr., pp. 352-433.

Parsons, Talcott, and A. L. Kroeber (1958): The Concepts of Culture and Social System, in: American Sociological Review 23, pp. 582-583.

Rehberg, Karl-Siegbert (1986): Kultur versus Gesellschaft? Anmerkungen zu einer Streitfrage in der deutschen Soziologie, in: Friedhelm Neidhardt, M. Rainer Lepsius und Johannes Weiß (eds.), Kultur und Gesellschaft. Kölner Zeitschrift für Soziologie und Sozialpsychologie, Sonderheft 27, Opladen: Westdeutscher Verlag, pp. 92-115.

Spencer-Brown, George (1994): Laws of Form, lim. ed., Portland, Ore.: Cognizer Co.

Tarde, Gabriel (1962): Laws of Imitation, transl. Elsie Clews Parsons, Gloucester, Mass.: P. Smith.

Tarde, Gabriel (1969): On Communication and Social Influence, transl. Terry N. Clark, Chicago: Chicago UP.

Turner, Frederick (1997): Chaos and Social Science, in: Raymond A. Eve, Sara Horsfall, and Mary E. Lee (eds.), Chaos, Complexity, and Sociology: Myth, Models, and Theories, Thousand Oaks, CA: Sage, pp. xi-xxvii.

Von Bertalanffy, Ludwig (1968): General System Theory: Foundations, Developments, Applications, rev. ed., New York: Braziller.

Von Foerster, Heinz (2002): Der Anfang von Himmel und Erde hat keinen Namen: Eine Selbsterschaffung in 7 Tagen, eds. Albert Müller and Karl H. Müller, Reprint Berlin: Kulturverlag Kadmos.

Von Foerster, Heinz (2003): Understanding Understanding: Essays on Cybernetics and Cognition, New York: Springer.

Von Neumann (1958): The Computer and the Brain, New Haven: Yale UP.

Weaver, Warren (1948): Science and Complexity, in: American Scientist 36, pp. 536-544. 
Wellman, Barry (1988): Structural Analysis: From Method and Metaphor to Theory and Substance, in: idem and S. D. Berkowitz (eds.), Social Structures: A Network Approach, Cambridge: Cambridge UP, pp. 19-61.

White, Harrison C. (1992): Identity and Control: A Structural Theory of Action, Princeton, NJ: Princeton UP.

White, Harrison C. (2000): Parameterize! Notes on Mathematical Modeling for Sociology, in: Sociological Theory 18, pp. 505-509.

White, Harrison C. (2007): Networks and Meanings: Styles and Switchings, a Talk at the Conference "Ten Years After: Niklas Luhmann's Die Gesellschaft der Gesellschaft", Lucerne, Switzerland, December 7, 2007.

White, Harrison C. (2008a): Identity and Control: How Social Formations Emerge, $2^{\text {nd }}$ ed., Princeton, NJ: Princeton UP.

White, Harrison C. (2008b): Notes on the Constituents of Social Structure, Soc. Rel. 10 - Spring '65, in: Sociologica: Italian Journal of Sociology on line, no. 1.

White, Harrison C., Scott A. Boorman, and Ronald L. Breiger (1976): Social Structure from Multiple Networks, Part I: Blockmodels of Roles and Positions, in: American Journal of Sociology 81, pp. 730-780.

White, Harrison C., and Frédéric C. Godart (2007): Stories from Identity and Control, in: Sociologica: Italian Journal of Sociology on line, no. 3.

Wiener, Norbert (1961): Cybernetics, or Control and Communication in the Animal and the Machine, $2^{\text {nd }}$ ed., Cambridge, Mass.: MIT Pr. 